\title{
Concave Shape Microstrip Patch Antenna using SRR for 5G Applications
}

\author{
Navneet Kaur, Surbhi Sharma, Jaswinder Kaur
}

\begin{abstract}
A single band microstrip-fed patch antenna is presented which contains the radiating structure having concave shape slots and split ring resonator loaded in the partial ground plane. This partial ground plane has been used to enhance the bandwidth of proposed antenna. Both the partial ground plane and radiating patch are perfect electric conductors. The patch is imprinted on a substrate named as Epoxy Glass FR-4 having thickness $1.6 \mathrm{~mm}$, relative permittivity 4.4 , and loss tangent 0.0024. The designed concave shape microstrip patch antenna $(M P A)$ is resonate at single frequency band from $3.4-3.8 \mathrm{GHz}$ with $400 \mathrm{MHz}$ bandwidth and corresponding return loss of -25dB. A parametric study has been performed for the concave shape slots located in the patch. Proposed MPA is simulated using Computer Simulation Technology Microwave Studio Version 14.0 (CST MWS V14.0). Furthermore, the radiation performance of antenna in terms of gain and radiation efficiency has been analyzed. The proposed antenna is having a peak gain of $3.2 \mathrm{~dB}$ and radiation efficiency of $94 \%$.
\end{abstract}

Index Terms: CST MWS V14.0, partial ground plane, fifth generation, microstrip patch antenna, SRR.

\section{INTRODUCTION}

The fifth generation (5G) is the upcoming generation of mobile generation. It can operate in three different frequency spectrum below $1 \mathrm{GHz}$; mid range 1-6 GHz and millimeter frequency (mm-wave) band (3-300 GHz) [1]. The mid range 1-6 GHz spectrum is taking a great interest due to larger wavelength and available base station sites. In the mid range spectrum, 3.4-3.8 GHz band is focused by maximum countries ,as it is easy to implement with current technology[2].

In the recent literature [3-4], antenna have been designed for $\mathrm{mm}$-wave bands for $5 \mathrm{G}$ applications. But, atmospheric losses are major concern at these bands, therefore these proposed antennas are not suitable for long distance communication. To solve this propagation problem, different single element and MIMO antennas have been reported for mid range below $6 \mathrm{GHz}$ band [5-7]. In [5], a single element planar circularly polarized $5 \mathrm{G}$ antenna has been designed for S-band (3.6-4 $\mathrm{GHz}$ ) applications. In this designed antenna, thickness of antenna is very high of the order of $27 \mathrm{~mm}$ and the complete range of S-band ( 2 to $4 \mathrm{GHz}$ ) has not been covered.

Revised Manuscript Received June 24, 2019.

Navneet Kaur, PhD Student, Department of Electronics and Communication Engineering, Thapar Institute of Engineering and Technology, Patiala (Punjab), India.

Dr. Surbhi Sharma, Associate Professor, Department of Electronics and Communication Engineering, Thapar Institute of Engineering and Technology, Patiala (Punjab), India.

Dr. Jaswinder Kaur, Assistant Professor, Department of Electronics and Communication Engineering, Thapar Institute of Engineering and Technology, Patiala (Punjab), India.
In [6], a dual polarized dipole antenna for $2 \mathrm{G}, 3 \mathrm{G}, 4 \mathrm{G}$ and $5 \mathrm{G}$ application has been proposed. This antenna has been covered complete range of $5 \mathrm{G}$ band $(3.4-3.8 \mathrm{GHz})$. But at the same time overall height of antenna is very high of the order of $54 \mathrm{~mm}$ which is not suitable for $5 \mathrm{G}$ applications. In another study [7], a compact four element MIMO antenna is proposed for 3-4 GHz frequency band. However this antenna has been designed for complete range of $5 \mathrm{G}$ band with compact size. But the radiation performance of antenna has been degraded for whole band. The radiation efficiency of antenna at 3.15 $\mathrm{GHz}$ is $53.02 \%$.

To increase the radiation performance of antenna different technique has been proposed in the literature such as reflective surface [8], substrate integrated waveguide [9] and metamaterials [10]. From the study of these techniques, metamaterials are easy to use without affecting the overall size and bandwidth of antenna. Thus, in this work split ring resonator (SRR) has been etched from the ground plane of antenna to increase the radiation performance of antenna without affecting the S-parameters characterises of the proposed antenna. The proposed antenna has been designed for mid range below $6 \mathrm{GHz}$ band $(3.4-3.8 \mathrm{GHz})$ for $5 \mathrm{G}$ applications.

\section{GEOMETRY OF PROPOSED ANTENNA}

The proposed micro strip patch antenna (MPA) consists of a concave shape radiating patch on top of the substrate and a partial ground plane on the bottom of the substrate. The front and rear outlook of designed antenna is shown in Fig.1(a) and (b). The rectangular microstrip antenna of length $\mathrm{L}_{\mathrm{p}}=12 \mathrm{~mm}$ and width $\mathrm{W}_{\mathrm{p}}=16 \mathrm{~mm}$ is designed with the epoxy glass FR-4 substrate having dimensions $\mathrm{L}_{\mathrm{s}} \times \mathrm{W}_{\mathrm{s}} \times \mathrm{H}_{\mathrm{s}}=28 \times 34 \times 1.6 \mathrm{~mm}^{3}$, relative permittivity, $\varepsilon_{\mathrm{r}}=4.4$ and loss tangent, $\tan \delta=0.0024$. Microstrip feed Line having 50-ohm characteristics line impedance has been used to fed the proposed antenna. It is one of the simplest feeding technique. The initial design calculation of rectangular patch at resonating frequency of $3.6 \mathrm{GHz}$ is made by transmission line model equation [11]. The geometry calculation formulas are given below:

$$
L=L_{e f f}-2 \Delta L
$$

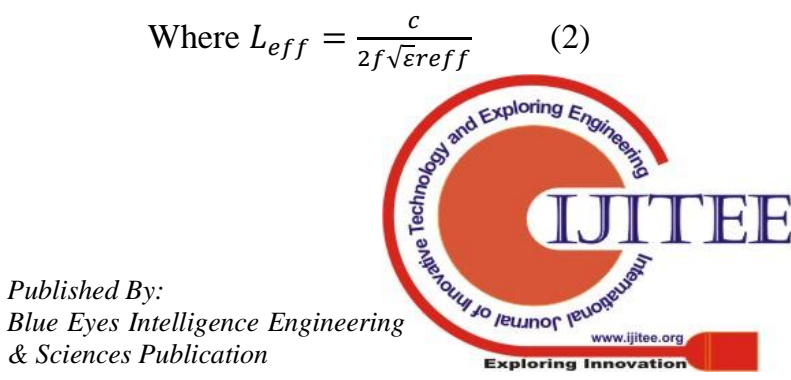




$$
\begin{aligned}
& \varepsilon_{\text {reff }}=\frac{\varepsilon_{r}+1}{2}+\frac{\varepsilon_{r}-1}{2}\left|\frac{1}{2 f \sqrt{1+12 \frac{h}{w}}}\right| \\
& \Delta L=0.412 \frac{\left[\varepsilon_{\text {reff }}+0.3\right]\left[\frac{h}{w}+0.264\right]}{\left[\varepsilon_{\text {reff }}-0.258\right]\left[\frac{h}{w}+0.8\right]} \\
& W=\frac{c \sqrt{2}}{2 f \sqrt{\varepsilon_{r}+1}}
\end{aligned}
$$

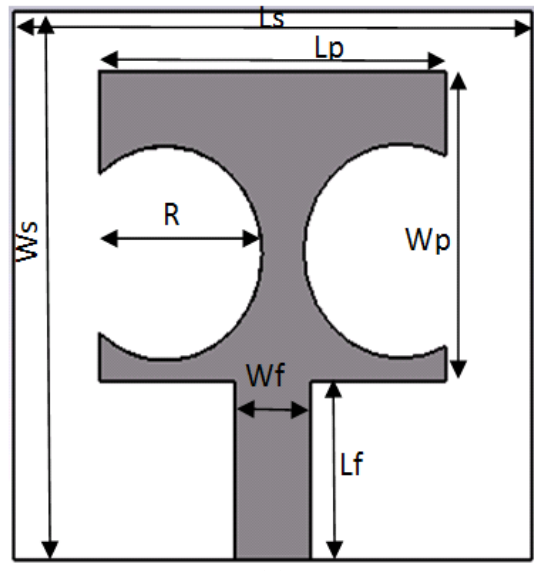

(a)

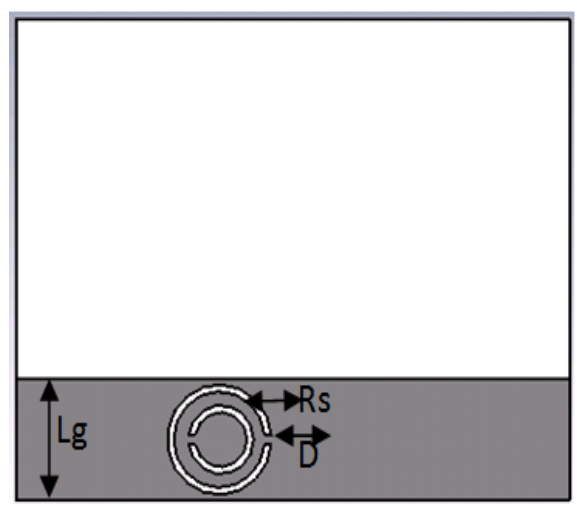

(b)

Fig.1. Geometrical configuration of the proposed antenna (a) Front view (b) Back view

From the above mentioned equations, we have found calculated length and width of basic rectangular patch are as : $\mathrm{W}=25.41 \mathrm{~mm}$ and $\mathrm{L}=19.41 \mathrm{~mm}$. But , in the proposed antenna the size of patch is miniaturized about $90 \%$ as compared to basic rectangular patch antenna in terms of frequency at 3.6 $\mathrm{GHz}(3.4-3.8 \mathrm{GHz})$ band. For the miniaturization purpose , two concave shape slots has been cut from the outer edge of rectangular antenna. Both slots are resonant at same frequency due to similar radius. The radius of slots has been optimized using parametric sweep window of simulation software.

Partial ground plane has been used to attain the desired bandwidth of $400 \mathrm{MHz}$ for $5 \mathrm{G}$ applications. Its length has been adjusted a number of times with hit and trial approach and finally the optimized length of the partial ground plane taken as length $\mathrm{Lg}=7 \mathrm{~mm}$. Further, a basic split ring resonator (SRR) has been loaded near the feedline of antenna to increase the radiation performance of antenna in terms of gain. Its position, radius and distance has been optimized by parametric sweep. Based on finite integration technique, CST MWS V14.0 software has been used for the examination and optimization of geometrical specifications of the proposed antenna. Transient solver in the main menu contains a parameter sweep option, which execute the analytical experimental repetitions with regulated time. Finally, for the proposed configuration, the optimal parameters obtained are depicted in Table 1.

TABLE 1 Optimal parameters of the proposed MPA antenna

\begin{tabular}{|l|l|}
\hline Parameters & Value $(\mathrm{mm})$ \\
\hline $\mathrm{L}_{\mathrm{p}}$ & 12 \\
\hline $\mathrm{W}_{\mathrm{p}}$ & 16 \\
\hline $\mathrm{R}$ & 4.5 \\
\hline $\mathrm{W}_{\mathrm{s}}$ & 34 \\
\hline $\mathrm{L}_{\mathrm{s}}$ & 28 \\
\hline $\mathrm{W}_{\mathrm{f}}$ & 3 \\
\hline $\mathrm{L}_{\mathrm{f}}$ & 8 \\
\hline $\mathrm{L}_{\mathrm{g}}$ & 7 \\
\hline $\mathrm{R}_{\mathrm{s}}$ & 0.5 \\
\hline$D$ & 0.5 \\
\hline
\end{tabular}

\section{ANTENNA SIMULATION RESULTS}

\section{A. S-parameter}

S-parameter is the difference between forward and reflected power. The simulated results of S-parameters with and without partial ground for the proposed antenna are depicted in Fig. 2.

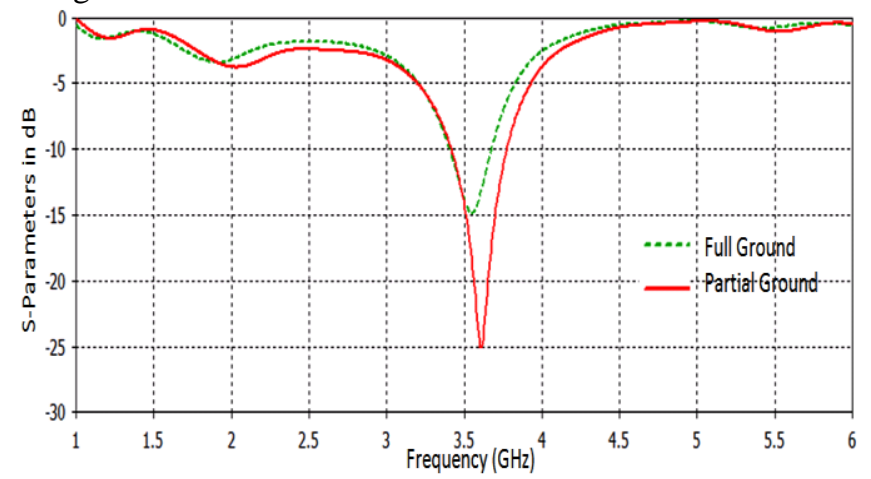

Fig.2. Simulated $S_{11}$ parameter versus frequency plots for proposed MPA full and partial ground plane

From Fig. 2, it is analyzed that that the antenna with full ground plane shows a $\mathrm{S}_{11}$ of $-15.0 \mathrm{~dB}$ at the resonating frequency $3.53 \mathrm{GHz}$. Also, the obtained simulated bandwidth for the resonating band at $3.53 \mathrm{GHz}$ is $277 \mathrm{MHz}$. Whereas in case of partial ground plane, the $S_{11}$ has been shifted at -25 $\mathrm{dB}$ along with $400 \mathrm{MHZ}$ bandwidth in the desired $5 \mathrm{G}$ application band $(3.4-3.8 \mathrm{GHz})$.

Published By:

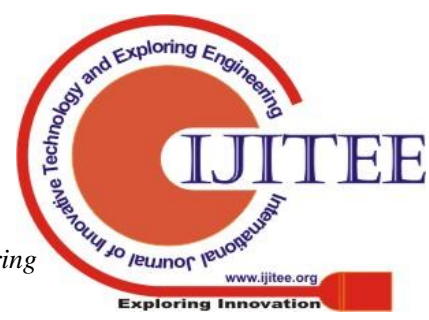


In addition to partial ground plane, two concave shape slots of the patch plays a significant role for achieving desired band. Therefore parametric study of the radius of these slots has been given in following section

\section{B. Effect of radius of concave slots in patch}

The effect of radius of concave slots in patch on the resonating band of proposed MPA antenna is illustrated in Fig. 3. Firstly, the radius $\mathrm{R}$ of the concave shape slots of the MPA is varied from 3.5 to 5 with step width of $0.5 \mathrm{~mm}$ which shows the decrease in return loss as the radius of the slots decreases from $4.5 \mathrm{~mm}$, as depicted in Fig. 3. Also, the band at $3.6 \mathrm{GHz}$ shifts towards right with decrease in the radius. Further, the radius of slots is increased from $4.5 \mathrm{~mm}$ to get the optimized results. But as the radius increases from $4.5 \mathrm{~mm}$ the S-parameters degrades with shifted resonating band. The best optimized result is observed at $\mathrm{R}=4.5 \mathrm{~mm}$ for $5 \mathrm{G}$ applications (3.4-3.8 GHz) band.

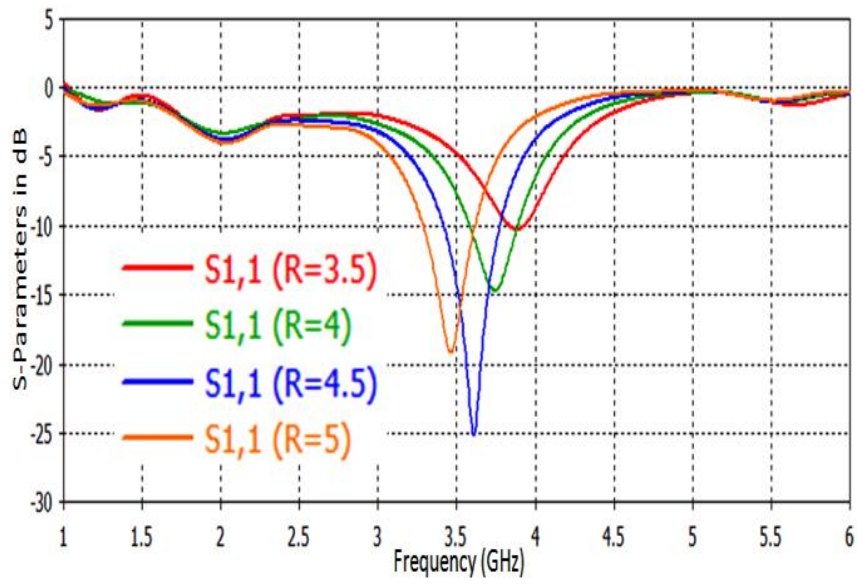

Fig. 3. Variations in the resonant frequency and return loss with change in radius $(\mathrm{R})$ of the proposed MPA antenna

\section{Surface Current}

To demonstrate more clearly the function of concave shape slots and SRR rings the surface current distribution is illustrated in Fig. 4. As shown in figure, the concentration of surface current is high at the centre of concave slots at 3.6 $\mathrm{GHz}$ frequency in the patch. Whereas in the ground plane, current distribution is high at SRR ring.

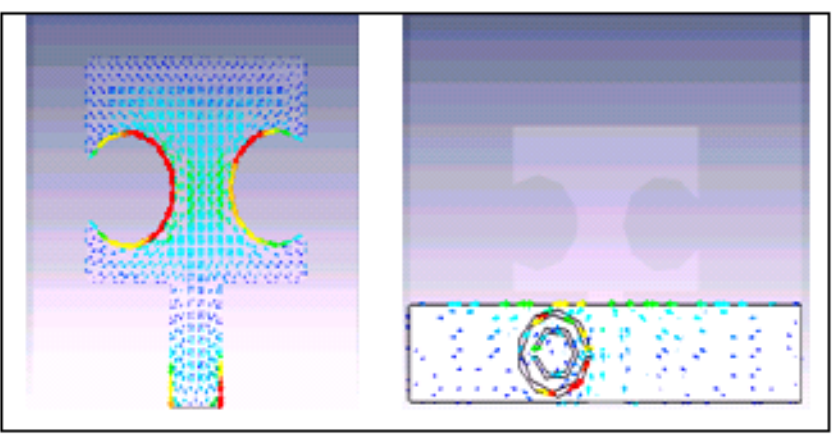

Fig. 4. Surface current distribution at $3.6 \mathrm{GHz}$

\section{Radiation Performance}

Retrieval Number: I1 1200789S19/19@BEIESP DOI: 10.35940/ijitee.I1120.0789S19
SRR has been loaded in the proposed MPA antenna design to improve the radiation characteristics of antenna in terms of gain and radiation efficiency. The maximum gain over frequency plot is shown in Fig. 5. It can be observed from given plot is that SRR plays a vital role to increase the gain of proposed antenna in the desired band.

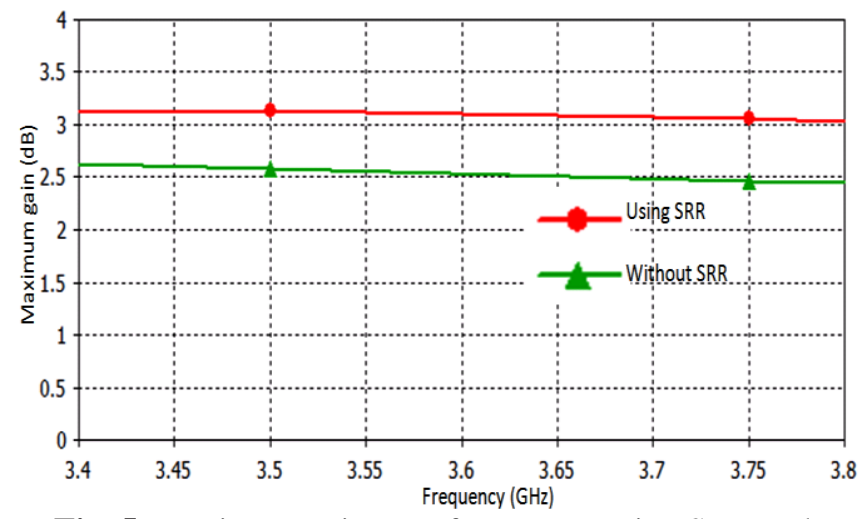

Fig. 5. Maximum gain over frequency using SRR and without SRR

In addition to gain, radiation efficiency of the proposed antenna is also increased using SRR. In Fig. 6, radiation efficiency graph over frequency is illustrated.

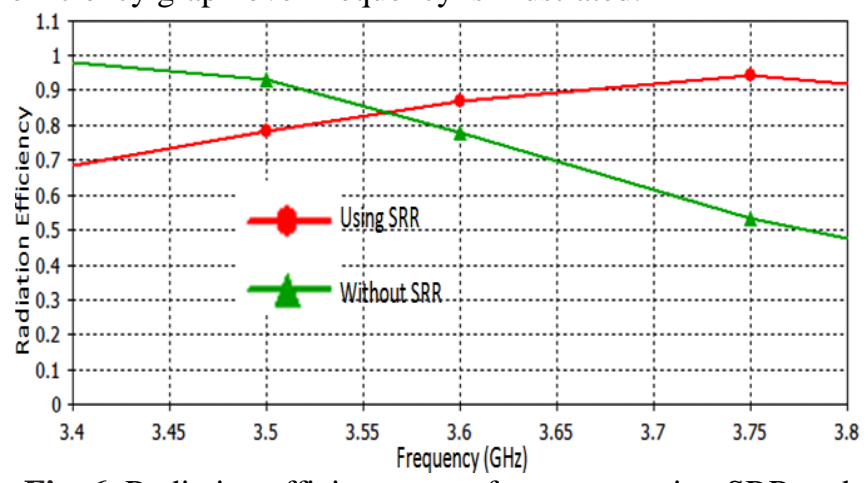

Fig. 6. Radiation efficiency over frequency using SRR and without SRR

Further, the results of radiation performance of proposed antenna with and without SRR is tabulated in table II.

TABLE II Comparison of radiation performance of the proposed MPA antenna with and without SRR at $3.6 \mathrm{GHz}$.

\begin{tabular}{|l|l|l|}
\hline Parameters & Gain $(\mathrm{dB})$ & Radiation Efficiency \\
\hline With SRR & 3.2 & $>70 \%$ \\
\hline Without SRR & 2.6 & $>49 \%$ \\
\hline
\end{tabular}

The simulated radiation pattern of proposed MPA at $3.6 \mathrm{GHz}$ frequency is depicted in Fig. 7. It is observed that the radiation pattern is 8 shape in E-plane and omni-directional in H-plane.

Published By:

Blue Eyes Intelligence Engineering \& Sciences Publication

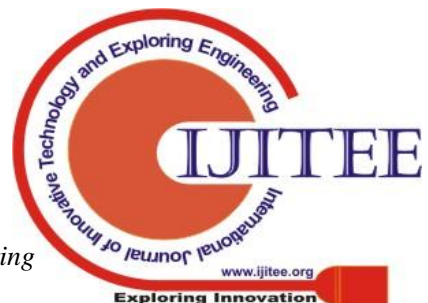




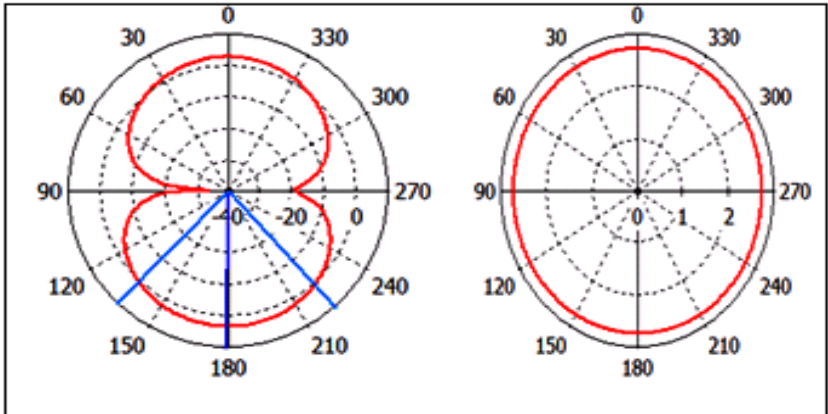

Fig. 7. Simulated radiation pattern at $3.6 \mathrm{GHz}$ for proposed MPA

\section{CONCLUSION}

A compact single-band concave shape MPA with SRR loaded in the partial ground plane has been designed in this paper that covers the mid range 3.4-3.8 GHz band for $5 \mathrm{G}$ applications. To improve the impedance bandwidth and miniaturization of the propose antenna, partial ground plane and two concave shape open ended slots have been introduced in the proposed MPA antenna. The proposed antenna structure is compact in size and having good radiation performance in the desired band. These properties of antenna is make suitable for $5 \mathrm{G}$ applications.

\section{REFERENCES}

1. A. Osseiran et al., "Scenarios for 5G mobile and wireless communications: the vision of the METIS project," in IEEE Communications Magazine, vol. 52, no. 5, May 2014, pp. 26-35.

2. Nokia white paper. 2017. 5G deployment below 6 GHZ. https://resources.ext.nokia.com/asset/201315.(accessed August 2017).

3. O. M. Haraz, A. Elboushi, S. A. Alshebeili and A. Sebak, "Dense Dielectric Patch Array Antenna With Improved Radiation Characteristics Using EBG Ground Structure and Dielectric Superstrate for Future 5G Cellular Networks," in IEEE Access, vol. 2,2014, pp.909-913.

4. K. Mak, K. So, H. Lai and K. Luk, "A Magnetoelectric Dipole Leaky-Wave Antenna for Millimeter-Wave Application," in IEEE Transactions on Antennas and Propagation, vol. 65, no. 12,Dec.2017, pp. 6395-6402.

5. K. M. Mak, H. W. Lai, K. M. Luk and C. H. Chan, "Circularly Polarized PatchAntenna for Future 5G Mobile Phones," in IEEE Access, vol. 2, pp. 1521-1529, 2014.

6. Alieldin, Ahmed, Yi Huang, Stephen J. Boyes, Manoj Stanley, Sumin David Joseph, Qiang Hua, and Dajun Lei. "A Triple-Band Dual-Polarized Indoor Base Station Antenna for 2G, 3G, 4G and Sub-6 GHz 5G Applications." IEEE Access 6 (2018): 49209-49216.

7. Sarkar, Debdeep, and Kumar Vaibhav Srivastava. "Four Element Dual-band Sub-6 GHz 5G MIMO Antenna Using SRR-loaded Slot-Loops." In 2018 5th IEEE Uttar Pradesh Section International Conference on Electrical, Electronics and Computer Engineering (UPCON), pp. 1-5. IEEE, 2018.

8. Vaidya, Avinash R., Rajiv K. Gupta, Sanjeev K. Mishra, and Jayanta Mukherjee. "Right-hand/left-hand circularly polarized high-gain antennas using partially reflective surfaces." IEEE antennas and wireless propagation letters, vol. 13, 2014, pp. 431-434.

9. Pandit, Soumen, Akhilesh Mohan, and Priyadip Ray. "A low-profile high-gain substrate-integrated waveguide-slot antenna with suppressed cross polarization using metamaterial." IEEE Antennas and Wireless Propagation Letters,vol. 16,2017, pp.1614-1617.

10. Singh, Amit K., Mahesh P. Abegaonkar, and Shiban K. Koul. "High-gain and high-aperture-efficiency cavity resonator antenna using metamaterial superstrate." IEEE Antennas and Wireless Propagation Letters, vol.16, 2017, pp. 2388-2391.
11. Balanis CA. Antenna Theory: Analysis and Design. Third Edition. Wiley Interscience. 2005.

\section{AUTHORS PROFILE}

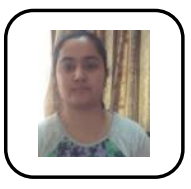

Navneet Kaur has obtained her Bachelor of Technology in Electronics \& Communication Engineering, DIET Kharar, Punjab, India and Masters of Technology in Electronics \& Communication Engineering from BGIET, Sangrur, India. Presently, she is pursuing PhD from TIET, Patiala. Her research interests includes, microwave transmission line, optimization, microstrip patch antenna \& 5 G MIMO .

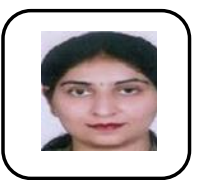

Surbhi Sharma completed her B.E. in electronics from RGPV Bhopal, M.E. from SLIET, Longowal and Ph. D. from Thapar Institute o Engineering and Technology , Patiala. Presently working as Associate Professor ,TIET, Patiala. She has published various papers in SCI/non SCI journals and national/ International conferences. Her areas of interest include MIMO systems, patch antenna, channel coding and SDR.

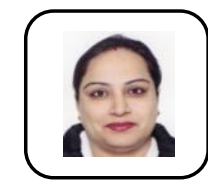

Dr. Jaswinder Kaur received her Ph.D. degree from, TIET, Patiala, in 2014. Her M.Tech. and B.Tech. degrees are from Punjab Technical University, Jalandhar, in 2009 and 2005 respectively. Presently she is working as an Assistant Professor, TIET., Patiala, Punjab, India. She has several publications in reputed national and international journals. Her research interests include communication, UWB antennas, 5G MIMO antennas, optimization of antennas using evolutionary algorithms, antennas for biomedical applications etc.

Published By: Blue Eyes Intelligence Engineering \& Sciences Publication

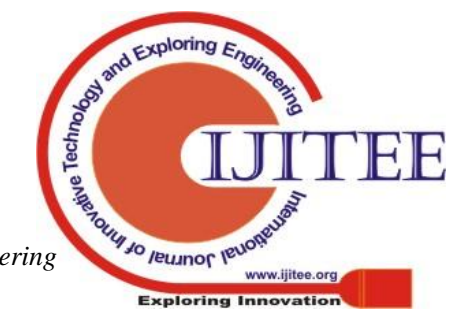

